\title{
IS CHRIST REALLY CONTRADICTORY? SOME METHODOLOGICAL CONCERNS FROM THE PHILOSOPHY OF SCIENCE ${ }^{1}$
}

\author{
MARÍA DEL ROSARIO MARTÍNEZ-ORDAZ ${ }^{1,2}$ \\ https://orcid.org/0000-0003-2118-3515 \\ ${ }^{1}$ Nicolaus Copernicus University in Torun \\ Department of Logic \\ Toruń \\ Poland \\ ${ }^{2}$ Federal University of Rio de Janeiro \\ Department of Philosophy \\ Rio de Janeiro, R.J. \\ Brazil \\ martinezordazm@gmail.com
}

\author{
Article info \\ CDD: 501 \\ Received: 16.06.2021; Accepted: 15.08.2021 \\ https://doi.org/10.1590/0100-6045.2021.V44N4.MO
}

\section{Keywords \\ Christ \\ Contradictory \\ Inconsistency Toleration \\ Scientific Theory}

\begin{abstract}
Two of the most important outcomes of The Contradictory Christ include: (i) identifying Christ as an unproblematically contradictory being as well as (ii) laying the foundations of an
\end{abstract}

1 This research was supported by the Programa Nacional de PósDoutorado PNPD CAPES (Brazil) and by the UNAM-PAPIIT Project IN403719 "Intensionalidad hasta el final: un nuevo plan para la relevancia lógica".

This work is the result of the book symposium on Jc Beall's The Contradictory Christ.

Manuscrito - Rev. Int. Fil. Campinas, v. 44, n. 4, pp. 313-339, Oct.-Dec. 2021. 
investigation of the logical consequences of the existence of Christ, qua contradictory, within a particular 'theory'.

In light of the enormous relevance of Beall's The contradictory Christ for the study of inconsistency, my main concern here is to explore the effect of some methodological choices behind Beall's proposal -this in order to recognize in more detail the scope of Beall's contribution. To do so, I will focus on three main questions: 1. What is required for the identification of a contradiction? 2. How can we recognize a true contradiction from either an apparent or a temporal contradiction? 3. If we identify a true contradiction within a theory, where can we actually go from there?

\section{Introduction}

A central thesis of The contradictory Christ (Beall 2020) is that Christ is an unproblematically contradictory being. The main reasoning behind this thesis goes as follows.

- First, Christ is contradictory because he has all of the limitlessness of God, and all of the limits of humans, he is also passible and impassible as well as capable of suffering and incapable of suffering, among others.

- Second, pace classical views on logic, the contradictory character of Christ is non-problematic as it doesn't seem to threaten sensible reasoning in any significant way. On the one hand, humans can keep reasoning sensibly from the inconsistent information that they have about Christ; on the other hand, and regardless of human cognitive achievements, the theories in which Christ is a contradictory entity, are unequivocally non-trivial.

- Third, Christ seems to be an essentially contradictory entity due to actually possessing two 
contrary natures, the one divine and the other human. Meaning that the contradictions that we associate to Christ correspond to some of his most fundamental features and that any correct understanding of Christ must include his contradictory character.

Given the above, Christ is not only an entity that can be described in an inconsistent manner, but is an entity that demands to be understood qua contradictory. In this sense, in any theory in which Christ exists and is contradictory, there would be some contradictions about him that are necessarily true.

Two of the most important outcomes of The Contradictory Christ include: (i) identifying Christ as an unproblematically contradictory being as well as (ii) laying the foundations of an investigation of the logical consequences of the existence of Christ, qua contradictory, within a particular 'theory'.

The richness of the book lies, at least partially, in providing an exemplar of a theory that contains a legitimate contradictory entity at its very core, and that, despite of being grounded in a contradiction, has remained explanatory successful -and has shaped the majority of dominant worldviews during the last two thousand years. In this regard, the novelty of Beall's proposal is that, even if there have been early attempts to identify a (non-formal) domain that legitimately demands to be described and explained through true contradictions, these attempts have systematically failed. If Beall's reconstruction of the contradictory Christ is correct, he might have identified such a domain.

In light of the enormous relevance of Beall's work for the study of inconsistency, my main concern here is to explore the effect of some methodological choices behind 
Beall's proposal -this in order to recognize, in more detail, the actual scope of his contribution.

In order to do so, I proceed in five steps. First, I discuss the methodology followed by Beall (2020) when recognizing and explaining the presence of contradictions about Christ, and I relate such a methodology to the one used in the philosophy of science literature when addressing inconsistency toleration in the sciences (Sect. 2). Later on, I focus on three main challenges. The first challenge is to analyze the sufficient conditions for the satisfactory identification of a contradiction and whether the contradictions about Christ that are discussed in The contradictory Christ were properly identified; I argue that problems remain (Sect. 3). The second challenge concerns the distinction between a true contradiction and either an apparent or a temporal contradiction ( Sect. 4). Later on, I discuss the challenge of determining what can be said, logically speaking, about a theory that contains a true contradiction (Sect. 5). Finally, I present some final thoughts (Sect. 6).

\section{The methodological roots}

There are fundamentally two ways of thinking about Christ, exemplified respectively by religious practice and ritual on the one hand and philosophical and scientific inquiry on the other, with some thinkers like Kierkegaard and Wittgenstein aiming to bridge those approaches. They exemplify two different approaches to religious concepts and ideas:

- An approach based on faith plus community, where those brought together by that faith commit themselves to observe certain practices and rituals. 
- An approach aimed at the rational investigation of the claims made in religious texts and practices, aimed at investigating and clarifying the nature of the objects and narratives of religious worship. ${ }^{2}$

Beall's work is more in line with the second sort of approach. His main contribution is the application of techniques and ideas from the philosophy of logic to religious questions and puzzles. But these puzzles emerge from this treatment of religion as a domain of inquiry susceptible to rational investigation, just the sort of approach ejected by thinkers like Kierkegaard and Wittgenstein.

Since these types of approaches are committed to taking the religious domain as susceptible of rational investigation they are themselves open to methodological critique, unlike religious rituals and practices which while open to ethical criticism (in some instances) cannot he said to be "truth-apt" unlike the claims of deistic thinkers that are in the business of interpreting religion as about the world 3 .

When religious claims are interpreted in the above manner they are theoretical claims: claims about what sorts of objects there are and what are their properties and relations, where Christ is treated as a theoretical entity which lives in a very specifically constrained world, and such a world can be explored through the analysis of the relations that allow for correct descriptions, explanations and predictions of what occurs in that world. In this sense, Beall's approach to Christ takes Christ to be a theoretical

\footnotetext{
${ }^{2}$ I am fully aware of the fact that there is an ongoing philosophical debate about the methodology for determining the meaning of religious language, however, as Beall does not focus on such debate, I believe this will suffice for the purposes of the paper.

${ }^{3}$ Thanks to Moisés Macías-Bustos, who helped me to give a better phrasing of my ideas on this point.
} 
entity that is either postulated, described or explained by the theory of Christology. In addition, Christology is seen as a theory that provides us with the general picture of the world in which Christ exists, regardless of whether this picture coincides with our actual world.

For these reasons, according to Beall's approach, Christology works as a kind of scientific theory and Christ is seen as a fundamental entity of the ontology that the theory postulates. As a matter of fact, Bell makes this connection explicit when saying that,

Christian theology is a theory of God, just as macro physics is a theory of the macro-physical world and just as mathematical theories are theories of their respective mathematical phenomena (numbers, categories, sets, whathaveyou. (Beall 2020:23)

In this sense, Beall's project is in good company. During the last decades, much attention has been paid to the role and authenticity of inconsistency in science. It has been claimed that, in scientific contexts, contradictions are not as dangerous as once feared they were, and even that they are quite common in scientific activity. This perspective has been enriched by the study of paraconsistent logics and the emergence of case studies from the history of science that seem to illustrate how the presence of some contradictions do not necessarily mean the logical explosion of the theory in question. ${ }^{4}$

4 Principle of Explosion (PE) is one of the most characteristic principles of classical logic (and of any other explosive logic), it says that any (explosive) theory will trivialize if it contains at least one contradiction. A contradiction is a pair of propositions, where one is the negation of the other. A theory is trivial if it is possible to derive any proposition from it. Therefore, any inconsistent 
A according to many paraconsistent logicians, scientific theories can be, and have been, inconsistent without thereby endangering the rationality of those who use them. The history of science contains sufficient evidence that proves that contradictions have been tolerated for long periods, and that during these periods, scientists have used efficiently their their inconsistent theories to describe, predict and even explain phenomena (cf. Smith 1988, Brown, 1990; Bueno 1997, 2006; Batens 1998, 2002; Meheus 2002; Priest 2002; Martínez-Ordaz 2017, 2020).

The work done in the philosophy of science has shed important light on the phenomenon of working with inconsistent information while avoiding logical triviality at the same time. This phenomenon has been called inconsistency toleration. In the case of human reasoning, this phenomenon consists of identifying a contradiction in a piece of reasoning and still being able to reason sensibly with the inconsistent information, this is, remaining able to distinguish between the products of one's reasoning that are sensible given a particular context from those that are not. In addition, a theory is inconsistency tolerant, it would contain a contradiction and still be able to provide us with accurate and relevant measurements, predictions and explanations about a specific domain -this, without getting trivialized.

And while the project of searching for instances of inconsistency toleration in the sciences is clearly promising for both logicians and philosophers of science, it has not prospered as expected -at least for the logicians' side. Significant methodological mistakes have kept logicians

(explosive) theory will be trivial. A logical consequence relation is paraconsistent if it is non-explosive, this is, if it does not validate PE; and a formal theory is paraconsistent if, despite containing a contradiction, it is not trivial.

Manuscrito - Rev. Int. Fil. Campinas, v. 44, n. 4, pp. 313-339, Oct.-Dec. 2021. 
away from the primary goal, which has always been to, first, understand the phenomenon of inconsistency toleration in the sciences, and, only later, to identify the logics, if any, that can help to scrutinize such a phenomenon. However, according to some philosophers, when doing so, logicians had lost sight of the original goal and ended up exclusively "proposing alternative logics that might lurk in the background of scientific reasoning" (Cf. Brown and Priest 2015: 299. My emphasis); focusing their attention on their specific preferred logics and neglecting all evidence that might conflict with their philosophical commitments (Cf. Vickers 2013, Chap. 8).

With this in mind, the study of the presence of contradictions in the sciences has to provide explanations about (a) the legitimacy of the contradiction, this is, why is the 'paraconsistent' interpretation of a pair of propositions the most accurate interpretation of it; (b) the role that the contradiction plays either in a theory or in human reasoning and the way in which such a role justifies its toleration. And finally, it is necessary to provide an explanation of (c) which is the methodology behind a formal exploration of the consequences of such contradiction.

In what follows I show that (a)-(c) are not exclusive of the cases of inconsistency toleration in the sciences, but that in any other enterprise in which a paraconsistent interpretation of a phenomenon is addressed for formal purposes, it is mandatory to respond to them as well. In particular, I focus on the contradictory characterization of Christ made by Beall.

In sum, an important point regarding the similarities between Beall's approach and the works on inconsistent science is that, once Christology is characterized as a theory -of a scientific* spirit, it should be seen as an epistemic product significantly influenced by human agents. In particular, while theories might refer to mind-independent 
phenomena, the interpretations, the reconstructions and the uses of the theories are (at least, partially) constrained by agents' preferences and cognitive limitations. Even if not acknowledged in the book, this is a grounding constraint for Beall's view, especially given that, when choosing his approach, he had previously renounced the possibility of centering his proposal on religious rituals and practices justified in either dogma, solely revelation or any other mystical source.

The questions that I pose against Beall's view will assume the role that epistemic agents play in the identification, justification and acceptance of the contradictions associated to Christ's nature.

\section{What is required for the identification of a contradiction?}

To assert that Christ is an unproblematically contradictory being requires both the possibility of effectively identifying a contradiction and, at least, a tolerant attitude towards it. Regarding the former, when describing a contradiction, Beall takes a very intuitive approach to the matter saying that:

\section{A formal contradiction is any sentence of the form:}

it is true that $x_{\ldots . . .}$ and it is false that $\mathrm{x}$...

A contradictory being, as discussed above, is a being of whom some contradiction (per above) is true. 
However, this characterization is not enough for explaining how we actually interpret certain elements of a particular theory in such a way that we can recognize them as a contradiction. This, in light of the fact that some of the examples that Beall uses to support his claim are not explicitly of this form, but have to be additionally interpreted as such. For instance, to identify as a contradiction the proposition "Christ possesses all of the limitlessness of God, and Christ possesses all of the limits of humans" requires an additional interpretation that makes explicit that possessing the limitlessness of God implies the falsity of possessing the limits of humans, and vice-versa.

One possible way to justify the straightforwardness of the contradictory interpretation is to say that the propositions' content in itself suffices for informing our recognition of them as contradictory. If adopting a view like this one, one would be an advocate of the 'material inference' approach (see Kapitan 1982, Read 1994, Brigant 2010); this is, inconsistency would just mean what

is being stated is impossible, and this does not come in 'weak' and 'strong' forms. On this view, when Ralph Kroning said 'electron spin' in 1925 this was indeed inconsistent with relativity. (...)The conflict follows from the material content of Kroning statement and does not depend on any logical form. (Vickers 2013: 33)

Nonetheless, the main problem with the material content view is that in cases such as the Christ example, is that as the content of the propositions might vary from what we take it intuitively to be to what it actually means within the specific theory. As Christ is a very peculiar entity, it could be perfectly 
OK to assume that for this entity such properties do not conflict in any relevant sense -similarly to the way in which 'wave' and 'particle' do not conflict with each other when explaining the nature of of light in Quantum Mechanics but they would do it in classical theories. If something like this is the case, then the interpretation of these two propositions as a contradiction would be unjustified.

Another way to go when backing up the straightforwardness of the contradictory interpretation is to say that the logical form actually plays a significant role. Two of the main challenges that this alternative faces are to guarantee that, when we say "it is true that $x . .$. and it is false that x..." $\mathrm{x}$ actually means the same in both parts of the conjunction and that such conjunction is justified. As it has been recently pointed out by some philosophers of science, in many cases in which scientists have thought to identified a contradiction within their theory, when looking at it more closely, they have come to realize that it was just an apparent contradiction which resulted from, at least, one of the statements being simplified for practical purposes (cf. Vickers 2013, Davey 2014).

One of the most common examples of this is the alleged inconsistency in the Newtonian Early Calculus. According to the theory, "at different points in the calculation of a derivative infinitesimals had to be assumed to be both zero and non-zero" (Brown and Priest 2004: 379). This seems to be enough to justify a straight forward contradictory interpretation of infinitesimals; nonetheless, if one looks closely to what Newton had in mind when claiming this, one will realize that the inconsistency is only the result of a method that Newton developed for facilitating the operations within the theory but not the result of a characterization of infinitesimals as inconsistent entities (see Boyler 1949: 193). "In other words, Newton says, exposition in terms of indivisibles or infinitesimals is simply a 
convenient shorthand" (Edwards 1979: 226). Considering this, it has been suggested that the the use of 'is equal to zero' was not exactly the same in both parts of the alleged contradiction; in particular that the refined interpretation of Newton's instruction was that, at some points of a derivation, infinitesimals were to be different from zero and at some others, they were to be taken as if they were equal to zero (see Vickers 2013: 182-1991). In addition, as the seemingly conflicting assumptions were used in different steps of the proof there was still the question of how justified their conjunction really was. Of course, there is a sense in which if one wants to broadly sketch the Newtonian method, it will seem like a globally inconsistent recipe, but in a more refined analysis, one will see that there is no actual domain that demands for the two propositions to be taken as true in the exact same context.

While there are going to be important dissimilarities between the calculus and the Christ case, the question still stands: how do we know that in the case of Christ the contradiction is not the result of (or at least, is not driven by) our linguistic limitations to consistently express the nature of Christ? For the case of Christ is obvious that if there is any simplification involved, which would be the source of the contradiction, this might not have been placed as an inferential shortcut, but maybe as either a heuristics for us to deal more easily with the analyzed phenomena or the result of our cognitive and linguistic limitations. If this being the case, it seems clear that the contradiction that emerges from our simplifications might not have any real effect on the nature of Christ. 


\section{How can we recognize a true contradiction from either an apparent or a temporal contradiction?}

To engage in more detail with Beall's proposal, let's assume that the contradictions associated to Christ are indeed legitimate -this is, the elements of the contradiction actually conflict with each other and the conjunction is justified. Would this mean that they are true? Not necessarily.

Following the similarities with the researches carried out in the philosophy of science, one would see that the large majority of the contradictions that have been identified, even when legitimate, are very likely to not be true. Philosophers have largely agreed on the fact that ignorance plays an important role for determining when scientists can be rationally inclined to work with inconsistent information -in non purely formal disciplines. And when doing so, they have generally appealed to the following:

1. When having two scientific statements that contradict each other, scientists tend to assume that, at least, one of them is false (Laudan, 1977: 56).

2. If scientists are able to distinguish which of the conflicting propositions should be regarded as false due to being part of idealizations, fictions, among others-, then they would be able to explain how they could satisfactorily work on seemingly false information.

3. However, most of the time, when confronted with an inconsistent set of information, scientists ignore, at least, which of the mutually contradictory statements should be regarded as false (cf. Bueno, 1997, 2006; Brown, 1990; Priest, 2002).

4. Once this ignorance is acknowledged, if scientists have no better alternative to the inconsistent set of 
propositions, the toleration of the contradiction becomes the only option at hand -such a tolerant attitude towards contradictions is often seen by scientists as a temporary resource.

Call this the generic explanation. (Martínez-Ordaz 2020: 2)

In light of the first premise of the generic explanation, the legitimate contradictions found in scientific practice are often expected to be at least partially false. And in light of the fourth premise of the explanation, inconsistent theoretical representation of phenomena are only acceptable in absence of equally virtuous consistent alternatives.

Beall's proposal deals with premises 1 and 4 simultaneously when discussing the epistemic mystery strategy.

Epistemic-mystery strategies, sometimes 'mysterian' strategies, involve a firm twofold commitment to the standard theory of logical consequence(...) together with an elaborate epistemological story to the effect that our current epistemic situation cannot but see the apparent contradictions in any viable candidates for the true (and sufficiently complete) christology (Beall 2020:145)

In a nutshell: Christ appears to be contradictory; the appearance is unavoidable in any available candidate for the true and sufficiently complete theory of Christ; but the theory is perfectly acceptable by standard norms because the apparent contradiction, though inevitable (in theories that we can formulate and understand), is only 
apparently contradictory; the apparent contradiction is due to equivocation the unwrapping of which is beyond our ken. (Beall 2020:146)

The similarities between the epistemic mystery strategy and the generic explanation include the role that (certain degree of) ignorance plays for the temporal tolerance of contradictions as well as the methodological importance of considering consistent alternatives to the inconsistent theory.

Beall's response to these concerns rests on the epistemically virtuous character of both inconsistent Christology and the contradictory nature of Christ.

- On the one hand, while it is common for humans to be mistaken about what seems to be obscure and seemingly inaccessible, we are very likely to be correct when asserting things that are obvious to us. In line with this, Beall says that "there's an old truism that if something looks like a duck, sounds like a duck, behaves like a duck, then, well, it's most probably a duck. One value of the saying is a methodological reminder: the best explanation of an appearance is often that the appearance is veridical" (Beall 2020: 147). Due to the reliability of our judgments about things that are obvious, the spirit of a heavy ignorance mediating the contradiction of Christ is dismissed. And appealing to simplicity, the epistemic superiority of the contradictory Christology is stated -if the contradictory nature of Christ is the most obvious interpretation of what is going on, we are very likely to be correct about it. Furthermore, if the nature of Christ is most likely to be contradictory, any theoretical approach that aims 
at representing Christ accurately must recognize his contradictory character.

- On the other hand, appealing to neutrality, Beall contends that "Contradictory Christology is neutral with respect to the true epistemology, or at least far closer to neutrality than any epistemic-mystery strategy can sustain."(Beall 2020: 148). With this in mind, contradictory Christology might not only be the most simple answer to the problem but the most robust approach to it as it will stand regardless which is discovered to be the true epistemology in the long run.

While Beall's response is interesting and seemingly intuitive, it still has two significant problems: first, we have an infinite number of instances that illustrate how our impressions of what is obvious, given our intuitions or our senses' reports, etc., might be very much mistaken. Second, we have overwhelming evidence in favor of the implausibility of true contradictions.

Take the first problem. Beall's account of obviousness seems to assume that our doxastic commitment with the legitimacy of the contradiction is of a very strong type. I take the idea behind Beall's stand point to be that we have critically and exhaustively examined the different (consistent and inconsistent) interpretations of what it means for Christ to be contradictory and we have reached the conclusion that to accept the contradictory nature of Christ is not only the most intuitive option, but actually the only one that enables our achievement of explanatory knowledge and understanding of Christ.

Now, take the later epistemic achievement, understanding. Understanding has been traditionally considered to "consist of knowledge about relations of 
dependence. When one understands something, one can make all kinds of correct inferences about it" (Ylikoski 2013: 100). In addition, understanding is often regarded as factive, this is, the content of understanding can only include true propositions. This considered, having the impression of understanding something that is knowingly imprecise, incoherent or false is called the illusion of depth of understanding' (see Ylikoski 2013, 2017). While such an illusion is clearly a mental confusion, according to some, certain defective (conflicting, inconsistent, false, impossible) elements can facilitate understanding if and only if they provide scientists "with epistemic access to true information that is difficult or even impossible to discern otherwise" (Lawler 2019: 26) - only in virtue of the true elements they shed light on. ${ }^{5}$

Assuming that the contradictory nature of Christ actually enables our achievement of knowledge and understanding, there are two alternative ways to explain why this is the case: either it does so in the same way in which an abstraction of the solar system will enhance our understanding, mostly as being an epistemic instrument, or it does so because of it being true. The first option will not please Beall, because the role that Christ plays in the ontology of Christology is a fundamental one (this is, is part of its most primitive ontology), thus it does not seem correct to treat his nature as the result of a simplification --something that, in contrast, the supporter of the epistemic mystery strategy might very easily accept. Therefore, if the assumption of Christ being contradictory is as epistemically fruitful as Beall argues it most be due to it being true. And this is where the second

${ }^{5} \mathrm{I}$ focus on the case of understanding because it is often thought to be the ultimate epistemic goal of our intellectual activities; however, all what has been said here can be argued for knowledge and other lower epistemic goods that require truth.

Manuscrito - Rev. Int. Fil. Campinas, v. 44, n. 4, pp. 313-339, Oct.-Dec. 2021. 
problem comes to the discussion, namely, the implausibility of true contradictions.

Dialetheists might disagree on both premise 1 of the generic explanation and the temporary character of inconsistency toleration -specially in the formal sciences. Nonetheless, the main problem for dialetheism has been to determine which are those exceptional contradictions that can be true. On this issue, even dialetheists agree on the fact that if true contradictions in the formal sciences are already extremely rare, they would be even more so in the empirical realm (see Priest, 1998: 423). As a matter of fact, the majority of contradictions that emerge in non-formal sciences are not true and this is why they are only temporarily tolerated until scientists find a consistent alternative (see Priest, 1998, 2002). As a result, even if dialetheism has been very useful for dealing with semantic paradoxes, it has severely struggled at finding exemplars of true contradictions in the empirical sciences. The morale is that the mere possibility of a specific contradiction being true is not enough for justifying inconsistency toleration in the empirical sciences. This considered, true contradictions do not pose a real challenge against the generic explanation. (MartínezOrdaz 2020: 3) ${ }^{6}$

${ }^{6}$ In recent years, Boccardi and Macías-Bustos (2017) have argued that not even the Hegelian theory of motion, the most famous case of a dialetheist empirical theory, is more successful predictively and explanatorily than its consistent rival, the Russellian account. This 
In light of the above, the supporters of Beall's account should provide an additional (and stronger) explanation for the truth of the contradictions about the nature of Christ, which explains what is actually distinctive of this case when comparing it to the neatest cases from the sciences. If what has been said here is along the right lines, the question is still how can we recognize propositions about the nature of Christ as true contradictions -and not as apparent or temporal inconsistencies.

\section{If we identify a true contradiction within a theory, where can we actually go from there?}

Let's assume that there are some propositions about Christ that are both inconsistent and true, the mandatory question is which is the effect that this has on the theory, in particular, what does the contradictory Christ says about the logical consequence relation under which the theory is closed.

First, theories are constrained by consequence relations that allow us to entail the consequences of the theory (such as predictions, explanations, etc.) and prevent us from obtaining irrelevant stuff/absurdities/etc. Second, if a theory contains a contradiction, and the corresponding logical closure is explosive, the theory will be trivial.

But hold on! If the theory appears, for all we can see, contradictory and is also closed under classical logic, the theory is trivial: it contains all sentences of the language of the theory,

shows how implausible it is for an empirical theory to be successful while containing true contradictions.

Manuscrito - Rev. Int. Fil. Campinas, v. 44, n. 4, pp. 313-339, Oct.-Dec. 2021. 
including not only each and every heretical sentence (Beall 2020: 148)

Third, if the theory contains a contradiction, and the theory is not trivial, we would be inclined to infer (abductively) that the logical closure is not explosive. While this reasoning seems to ground a significant part of Beall's project, we shouldn't accept it so straightforward.

According to [Michael 2016], paraconsistent logicians have provided a biased abductive argument to interpret the relation between what cases of inconsistent theories and the success of paraconsistent logics. "The idea here would be that there are interesting and productive inconsistent theories from which people do not infer random and unconnected conclusions; so, it might be thought, the logic they use does not licence such inferences" (Michael 2016: 3356). This reasoning goes as follows: from a particular case that illustrates temporal inconsistency toleration, abductively one infers that the best explanation of this toleration is that, either the reasoning of the agents using the theory or the theory in question, were closed under a paraconsistent logical consequence relation. Leaving as the only future task for the logicians to determine which is the specific paraconsistent logic that allows to better explain the particular case. Call this the abductive argument (in favor of paraconsistency).

There are two main methodological problems associated to this argument:

- The presumption of logical explosion: “This argument turns on what people in fact infer or should infer, so builds in a normative aspect. The first question which needs to be raised concerns the status of the 'should' in the claim about whether 
they should have inferred random sentences from the theory" (Michael 2016: 3357).

This has negative effects in two senses: on the one hand, it weakens the empirical (historical) adequacy of paraconsistentist explanations of inconsistency toleration. On the other hand, at a methodological level, it reveals an important bias that affects the legitimacy of the relationship between historical evidence and the applicability of some paraconsistent tools.

- The presumption of logical closure: The paraconsistent, especially the dialetheist, explanation takes logical triviality to be a challenge for inconsistency toleration basically because it assumes that human rationality is expected to obey logical principles, such as Principle of Explosion. However, at this point, there is significant literature arguing otherwise. Epistemic agents respond to inferential challenges, such as inconsistencies, using pragmatic reasoning strategies that help them to solve particular problems in specific contexts and that do not privilege determined theories of inference (Cf. Harman 1984: 108, Michael 2016: 3355-57).

So, at a methodological level, this abductive inference seems unjustified for two reasons. First, it relies heavily on empirical evidence that is never provided - regarding the logical closure of human cognition. And second, it assumes that all cases of tolerance to contradiction are, at least, structurally uniform, and therefore, the explanation of the mechanisms that allowed such tolerance in one specific case would be the same for any other case. 
Beall's response to these complaints might be that, while one can grant that human rationality does not strictly obey logical principles, theories as abstract complex entities very well might. And so, the attention must focus on whether the contradictory Christology is a trivial theory or not. And as we have enough evidence of it not being trivial, we can move forward to investigate which are the structural constraints that allow for the theory to have at its core a contradictory entity and still be successful.

However, this response is still problematic. First of all, projects about exploring the logical constrains of (nonformal) theories are challenged by our cognitive limitations. While we might very well identify certain inferential processes, many more will remain episodically opaque to us, dooming fine grained analyses of the theories and their consequences (see Putnam 1981).

Furthermore, the contradictory Christology is an extremely peculiar theory among theories, as, given the object of its study, it aims at being as general and as total as possible.

When theorists aim to construct a true theory, they aim to construct as complete a theory as possible. In particular, the resulting theory should not only contain the initial thrown-in truths (e.g., that God is triune, that Christ has two natures, etc.); the theory should also contain whatever follows from the truths in the theory; ; it should contain all of the consequences of the theory's claims. The question is: what is meant by 'follows from' and 'consequences' in this context? (Beall 2020:23)

This must, definitely, have an impact on the epistemic access that we might have to the theory's structural constraints. 
Having as a result that, as Harman(1984) and Michael(2016) have suggested epistemic agents will be able to only distinguish certain reasoning strategies that help them to solve particular problems in specific contexts and that do not privilege determined theories of inference. This takes us back to the initial concern about human reasoning.

If the theory of contradictory Christology is so complex that we cannot scrutinize it to its core, the only hints that we might have about its inferential constraints will be the ways in which agents reason with the theory's information, this is, the ways in which they use fragments of the theory. These common uses can be described in terms of sets of strategies or general procedures that are explanatory of the way in which it is possible to handle specific contradictions in order to avoid logical explosion. ${ }^{7}$ These strategies suggest ways in which information could be broken apart and transmitted while following some inferential patterns. Even though these strategies often substantiate the general dynamics of certain logics; they are, most of the time, also logic-independent this is, they are compatible with many and diverse logical consequence relations.

And so, by studying them we might only reach the conclusion that either the logical consequence relation of the theory is non-explosive or that agents have been able to, regardless of the theory's logical closure, use the theory in an non-explosive way.

The final question is, even if we identify a true contradiction within a theory, where can we actually go from there? How can we escape the constrained realm of agents' reasoning to say something more general about the

${ }^{7}$ Such strategies are paraconsistent in the sense that they allow scientists to avoid logical explosion in an optimal way -recognizing that what is 'optimal' would depend on the own constraints of each of the cases that are being studied.

Manuscrito - Rev. Int. Fil. Campinas, v. 44, n. 4, pp. 313-339, Oct.-Dec. 2021. 
inferential grounds of contradictory Christology and other inconsistent theories?

\section{Concluding remarks}

Beall's contradictory Christology faces a number of serious methodological flaws and, if they are not properly addressed, the proposal should be abandoned. While these objections seem to come from a different area of research, namely, philosophy of science, if neglected, they can undermine the scope of Beall's contribution in religious contexts. Here, I have dealt with three major concerns: first, the interpretation of any pair of propositions about the nature of Christ as a contradiction requires more methodological rigour; if not, the core thesis of Beall's account, that Christ is described through inconsistent propositions, is flawed (Sect. 3). Second, if there is no clear distinction between temporal and true contradictions, the case that Beall proposes in [The contradictory Christ] is only superficial. Finally, if not explained the role of human agents in recognizing and working with the contradictions about Christ, the contradictory Christology, and the logical projects that might emerge around it, are doomed.

\section{Acknowledgments}

I am indebted to Moisés Macías-Bustos for his valuable and fruitful constant feedback. I owe special thanks to Jc for his always kind engagement with my concerns and critiques. Thanks also to Diderik Batens, Susana Gómez, Andrew Tedder, Jean Yves Beziau, and the anonymous referees for their valuable comments. Thanks to the audience at the symposium "Discussing The Contradictory Christ" 
(UNAM). Finally, thanks to the editors for their assistance and their understanding.

\section{References}

1. Batens, D. (1998): "Paraconsistency and its relation to worldviews", Foundations of Science, Volume 3, Issue 2: 259--283.

2. Batens, D. (2002): "In Defence of a Programme for Handling Inconistency", in Inconsistency in Science , Kluwer Academic Publishers, Netherlands: 129-150.

3. Beall, Jc (2020). The Contradictory Christ, Oxford Studies in Analytic Theology.

4. Boccardi, E. and M. Macías-Bustos (2017). "Contradictions in motion: Why they're not needed and why they wouldn't help", HUMANA.MENTE Journal of Philosophical Studies, 10(32): 195-227.

5. Boyer, C.B. (1949). The history of the calculus and its conceptual development , New York Dover.

6. Brigandt, I. (2010). "Scientific reasoning is material inference: Combining confirmation, discovery and explanation", International studies in the philosophy of science 24(1): 31-43.

7. Brown, B. (1990): "How to be realistic about inconsistency in science", Studies in History and Philosophy of Science 21 (2): 281--294.

8. Brown, B. and G. Priest (2015): "Chunk And Permeate, A Paraconsistent Inference Strategy. Part I: The Infinitesimal Calculus", Journal of Philosophical Logic 33: 379--88 
9. Brown, B. $\$ \backslash \& \$$ G. Priest (2015): “Chunk and permeate II: Bohr's Hydrogen Atom", European Journal for Philosophy of Science Vol. 5, Issue 1: 1-18 .

10. Bueno, O. (1997): "Empirical Adequacy: A Partial Structures Approach", Studies in History and Philosophy of Science 28:585--610

11. Bueno, O. and S. French (2011): "How theories represent", The British Journal for the Philosophy of Science 62 (4): 857-894.

12. Davey, K. (2014): "Can good science be logically inconsistent?", Synthese ( S.I. Is Science Inconsistent? ) 191: 3009--3026.

13. Edwards, C. H. (1979). The historical development of the Calculus . New York: Springer-Verlag.

14. Harman, G. (1984). "Logic and Reasoning", Synthese, Vol. 60, No. 1, Foundations: Logic, Language, and Mathematics, Part I, pp. 107-127.

15. Kapitan, T. (1982). "On the concept of material consequence" History and Philosophy of Logic 3: 193-211.

16. Ylikoski, P. (2013): "The Illusion of Depth of Understanding in Science", in H. De Regt, S. Leonelli and K. Eigner (eds.) Scientific Understanding: Philosophical Perspectives, Pittsburgh University Press: 100-119.

17. Lakatos, I. (1978): The Methodology of Scientific Research Programmes: Philosophical Chapters , Vol. 1. Cambridge University Press.

18. Laudan, L. (1977): Progress and its Problems . Ewing, NJ: University of California Press. 
19. Lawler, I. (2019): "Scientific understanding and felicitous legitimate falsehoods:. Synthese .

20. Martínez-Ordaz, M. del R. (2020): “The ignorance behind inconsistency toleration", S.I. Knowing the unknown, Synthese.

21. Meheus, J. (2002): "How to reason sensibly yet naturally from inconsistencies", in Inconsistency in Science , Kluwer Academic Publishers, Netherlands: 151--164.

22. Michael, M. (2016): "On a "most telling” argument for paraconsistent logic", Synthese 193 (10).

23. Priest, G. (1987): In Contradiction: A Study of the Tranconsistent (1st edition), Clarendon Press. Oxford.

24. Priest, G. (1998): "What is so bad about contradictions?”, Journal of Philosophy 95 (8):410-426 .

25. Priest, G. (2006): Doubt truth to be a liar . Oxford: Oxford University Press.

26. Putnam, H. (1981). "The corroboration of theories", in Hacking, I. (ed) Scientific Revolutions, Oxford, NY: Oxford University Press: 121-137.

27. Šešelja, D. (2017): "Scientific Pluralism and Inconsistency Toleration”, Humana Mente 32: 1-29.

28. Smith, J. (1988): "Inconsistency and scientific reasoning", Studies in History and Philosophy of Science Part A 19 (4):429-445.

29. Vickers, P. (2013): Understanding Inconsistent Science, Oxford University Press.

EY 